\title{
THE EFFECT OF FATTY ACID PROFILE ON THE STABILITY OF NON- TRADITIONAL AND TRADITIONAL PLANT OILS
}

\author{
Josef Soukup, Lenka Kouřimská
}

\begin{abstract}
The effect of fatty acid composition on the autoxidation of selected plant oils (rapeseed (canola) oil, corn oil, frying oil, grapeseed oil, pomace olive oil, rice bran oil, sunflower oil and high oleic sunflower oil) during their storage was studied. Oils were purchased in retail food stores. Oxidative stability of plant oils was monitored during the storage under the Schaal test conditions at $60^{\circ} \mathrm{C}$ in $100 \mathrm{~mL}$ beakers and the dark for 40 days. The weight changes, the peroxide and acid values were analysed during the storage. Changes in the composition of fatty acids were analyzed by the gas chromatography-mass spectrometry. The results obtained by monitoring the weight changes of oils correlated with their peroxide values. The induction period in case of grapeseed and sunflower oils was 27 and 28 days respectively. The induction period for frying and rapeseed oils were around 35 days. The remaining four oils had induction periods over 40 days. The acid values at the end of experiment correspond to both the relative weight gain and the the peroxide values. The stability of oils depended mainly on the degree of fatty acids unsaturation. A strong negative correlation between oleic acid content and oil stability expressed as the peroxide value was found. The significant positive correlation was found in case of linoleic acid. The relative content of polyunsaturated fatty acids decreased during the storage while the content of saturated and monounsaturated fatty acids increased. The highest relative increase in oleic acid was found at the least stable oils, grapeseed and sunflower oils, by $37.5 \%$ and $25.3 \%$ respectively. The initial content of free fatty acids monitored by the acid value did not affect the oxidation rate. With consideration to all monitored parameters the grapeseed and the sunflower oils were the least stable. The most stable ones were olive pomace and high oleic sunflower oils.
\end{abstract}

Keywords: plant oil; autooxidation; oxidative stability; fatty acid; Schaal test

\section{INTRODUCTION}

Vegetable oils differ in both their origin and composition. They are made from seeds, grains, sprouts, nuts, etc. They consist mainly of triacylglycerols (97\%) which serve as a solvent for other lipophilic substances present in oils (sterols, fat-soluble vitamins - mainly tocopherols and tocotrienols, pigments including chlorophylls and carotenoids, phenolic compounds, phospholipids, free fatty acids and mono- and diacylglycerols). Oils differ in the degree of unsaturation, the type of triacylglycerol-forming fatty acids as well as the amount and type of unsaponifiable substances. These differences in composition are responsible for differences in oxidative stability of oils and their sensory and technological properties (Kamal-Eldin, 2006).

Oil stability is a resistance to oxidation during the processing and storage (Guillen and Cabo, 2002). It can be expressed as the time required to reach the critical point of oxidation, either in terms of sensory properties or the sudden acceleration of the oxidation process. Oxidation stability is an important indicator to determine the oil quality and its shelf life as the oxidation produces lowmolecular compounds that affect sensory quality. These compounds cause oil to become less acceptable or totally unacceptable both for consumers and for industrial use. During the oxidation, essential fatty acids are degraded and toxicologically undesirable compounds and oxidized polymers could be formed. Oxidation has a great effect on the taste, nutritional quality and safety of oils (Choe and Min, 2006; Matthäus, 2010; Angelovič et al., 2015).

Oil oxidation is influenced by many factors including fatty acid composition, processing, energy of heat or light, the presence, concentration and type of oxygen (triplet $-{ }_{3} \mathrm{O}_{2}$ and singlet - $\mathrm{1}_{2}$ ), free fatty acids, mono- and diacylglycerols, transition metals, peroxides, thermally oxidized compounds, pigments, and antioxidants. These factors interactively affect the oxidation of oil and it is hard to differentiate the individual effect of each of them. Edible oil is oxidized during autoxidation (triplet oxygen $-3 \mathrm{O}_{2}$ reacts with the oil) and photosensitized oxidation (singlet oxygen $-{ }_{1} \mathrm{O}_{2}$ reacts with the oil). Autoxidation of oils requires radical forms of acylglycerols, whereas photosensitized oxidation does not require lipid radicals $\mathrm{O}_{2}$ reacts directly with double bonds (Choe and Min, 2006; Matthäus, 2010; Žabčíková and Červenka, 2015). 
In order to minimize the oxidation of edible oil during the processing and storage, it is advisable to lower the temperature, exclude light and oxygen, remove metals and oxidized compounds, and use appropriate concentrations of antioxidants such as tocopherols and phenolic compounds (Choe and Min, 2006).

\section{Scientific hypothesis}

The stability of plant oils during the storage under increased temperature is affected by the composition of fatty acids.

\section{MATERIAL AND METHODOLOGY}

\section{Assessment of oil stability using the Schaal test}

The oils were stored in open $100 \mathrm{~mL}$ beakers at $60{ }^{\circ} \mathrm{C}$ and the weight changes indicating the amount of oxygen absorbed in the oil were recorded. The increase in mass reflects the degree of oxidation of the monitored oil.

\section{Materials and analytical equipment}

Oils were purchased in retail food stores. They were in one-liter clear plastic or colored glass bottles. All samples were odourless without any rancidity off-flavour and their expiry date was more than 10 months.

Corn oil: Made by Olitalia, via Meucci 22/A, Forli, Italy. The declared composition (per $100 \mathrm{~mL}$ of product) $-91 \mathrm{~g}$ of total fat, $13 \mathrm{~g}$ of saturated fatty acids (SFA), $23 \mathrm{~g}$ of monounsaturated (MUFA) and $55 \mathrm{~g}$ of polyunsaturated fatty acids (PUFA).

Grape seed oil: Made by Olitalia, via Meucci 22/A, Forli, Italy. The declared composition (per $100 \mathrm{~mL}$ of product) $91 \mathrm{~g}$ of total fat total, $10 \mathrm{~g}$ of SFA, $19 \mathrm{~g}$ of MUFA and $62 \mathrm{~g}$ of PUFA fatty acids.

Frying oil: Made by Palma Group, a.s., Račianska 76, Bratislava, Slovak Republic. Mixture of low-erucic rapeseed oil (canola oil) and high oleic sunflower oil. The declared composition (per $100 \mathrm{~mL}$ of product) $-91.3 \mathrm{~g}$ of total fat, $7.2 \mathrm{~g}$ of SFA, $75.8 \mathrm{~g}$ of MUFA and $8.3 \mathrm{~g}$ of PUFA. Olive-pomace oil: Made by Ondoliva, Urzante S.L., Ciudad, Agroalimentaria, Tudela (Navarra), Spain. The declared composition (per $100 \mathrm{~mL}$ of product) - $100 \mathrm{~g}$ of fat total, $13 \mathrm{~g}$ of SFA, $79 \mathrm{~g}$ of MUFA and $8 \mathrm{~g}$ of PUFA.

Rice oil: Made by Olitalia, via Meucci 22/A, Forli, Italy.

The declared composition (per $100 \mathrm{~mL}$ of product) - $91 \mathrm{~g}$ of total fat, $22 \mathrm{~g}$ of SFA, $38 \mathrm{~g}$ of MUFA and $31 \mathrm{~g}$ of PUFA, $200 \mathrm{mg}$ of $\gamma$-oryzanol and $16 \mathrm{mg}$ of vitamin.

Rapeseed (canola) oil: Made by COP, Prins Albertlaan 12, Izegem, Belgium. The declared composition (per $100 \mathrm{~mL}$ of product) $-100 \mathrm{~g}$ of total fat, $8 \mathrm{~g}$ of SFA, $62 \mathrm{~g}$ of MUFA and $30 \mathrm{~g}$ of PUFA.

Sunflower oil: Made by Fabio Produkt spol. s.r.o., Holin 92, Jičín, Czech Republic. The declared composition (per $100 \mathrm{~mL}$ of product) $-92 \mathrm{~g}$ of total fat, $10 \mathrm{~g}$ of SFA.

Sunflower oil with increased oleic acid content (organic farming product): Made by Rapunzel Naturkost, Legau, Germany. The declared composition (per $100 \mathrm{~mL}$ of product) $-100 \mathrm{~g}$ of total fat, $6 \mathrm{~g}$ of SFA, $79 \mathrm{~g}$ of MUFA (of which $79 \mathrm{~g}$ is oleic acid) and $15 \mathrm{~g}$ of PUFA.

\section{Analytical equipment}

Analytical balances AND, FR 200 MK II; capacity 210 g, resolution $\mathrm{d}=0.1 \mathrm{mg}$; thermostats Memmert 54853 and POL-EKO ST.

\section{Procedure}

Approximately $25 \mathrm{~g}$ of oil was weighed (with the accuracy to four decimal places) into the $100 \mathrm{~mL}$ beakers (two parallel samples from each oil). The beakers were placed in the thermostat set at $60{ }^{\circ} \mathrm{C}$ for 40 days. One series of samples was reguralry weighed and another series of the same samples was reguralry sampled for the peroxide and acid values determinations. The relative weight gain $(\Delta \mathrm{m})$ was calculated according to the formula:

$$
\Delta \mathrm{m}=\frac{m_{x}-m_{p}}{m_{x}}
$$

where $m_{x}$ is the weight of the oil at the day of weighing and $\mathrm{m}_{\mathrm{p}}$ is the weight of the oil at the beginning of the storage $($ day $=0)$.

\section{Peroxide value determination}

Peroxide value was used to monitor the amount of primary oxidation products produced during the Shaal tests. The determination is based on the reaction of the sample with potassium iodide solution in acetic acid and chloroform solution according to the ISO 3960:2017. The released iodine is then titrated with standard sodium thiosulphate. Determination is based on the reactions:

$$
\begin{aligned}
& \mathrm{ROOH}+2 \mathrm{I}-+2 \mathrm{H}_{+} \rightarrow \mathrm{I}_{2}+\mathrm{ROH}+\mathrm{H}_{2} \mathrm{O} \\
& \mathrm{I}_{2}+2 \mathrm{~S}_{2} \mathrm{O}_{32-} \rightarrow 2 \mathrm{I}-+\mathrm{S}_{4} \mathrm{O}_{62}-
\end{aligned}
$$

The results were expressed in millimoles of active oxygen per kilogram of oil. The peroxide number was measured at $0 ; 5 ; 10 ; 20 ; 30$ and 40 days of storage.

\section{Chemicals}

Glacial acetic acid p.a. 99.8\% (PENTA), chloroform p.a. (Lachner), potassium iodide p.a. (PENTA), sodium thiosulphate pentahydrate p.a. (Lachner), potassium dichromate, hydrochloric acid 35\% (Lachin), starch soluble p.a. (Lachema), distilled water.

\section{Acid value determination}

The acid value determination was used to monitor the changes in the amount of free fatty acids during the Shaal test. The method is based on the neutralization of free fatty acids by ethanolic potassium hydroxide solution according to the ISO 660:2009. The acid value was measured at days $0 ; 20$ and 40.

\section{Chemicals}

Diethylether p.a. (PENTA), ethanol 99.8\%, potassium hydroxide p.a. (Lachema), phenolftalein (Lachin), oxalic acid dihydrate p.a. (Lachema). 


\section{Determination of fatty acids profile by gas chromatography}

Gas chromatography was used to determine the fatty acid representation in fresh oils and oils stored for 40 days at $60{ }^{\circ} \mathrm{C}$ and to determine the changes of the fatty acid saturation during the oils rancidification. The base esterification method using $0.5 \mathrm{M}$ methanolic potassium hydroxide $(\mathrm{KOH})$ was used for fatty acid derivatisation. Methyl esters of the fatty acids were then analysed using gas chromatography-mass spectrometry Agilent 7890A GC coupled to Agilent 5975C single-quadrupole mass detector equipped with an Rt-2560 column $(100 \mathrm{~m} \quad \times$ $0.25 \mathrm{~mm}$ ID, $0.25 \mu \mathrm{m}$ film, Restek Corporation, Bellefonte, USA). Hexane was used as the solvent and $1 \mu \mathrm{L}$ of the sample was injected in the split mode (ratio 50:1) into the injector, which was heated to $225^{\circ} \mathrm{C}$. Starting at $70{ }^{\circ} \mathrm{C}$ for $2 \mathrm{~min}$, the oven temperature was increased at a rate of $5{ }^{\circ} \mathrm{C}$.min-1 to $225^{\circ} \mathrm{C}$ where it was kept constant for $9 \mathrm{~min}$, and then subsequently increased at a rate of $5{ }^{\circ} \mathrm{C}$.min-1 to a maximum of $240{ }^{\circ} \mathrm{C}$ where it was maintained for $25 \mathrm{~min}$. Helium was used as the carrier gas at a flow rate of $1.2 \mathrm{~mL} \cdot \mathrm{min}-1$. The MS analysis was carried out in full scan mode with a mass range of $40-400$ m.Z-1, and the electron ionization energy was set at $70 \mathrm{eV}$. The methylated fatty acids were identified using a Restek Food Industry FAME mix (cat. No. 35077) and by comparing their mass spectra with those reported in the National Institute of Standards and Technology Library (NIST, USA). The proportions of the fatty acids were calculated using the area normalisation method and expressed as relative percentage of all fatty acids.

\section{Chemicals and equipment}

Methanol (Scharlau), potassium hydroxide p.a. (Lachema), n-heptane (MERCK), sodium chloride p.a. (PENTA), sodium sulphate anhydrous pure (Lachema).

\section{Statistical analysis}

The data were processed using Microsoft Excel 2007 (Microsoft Corporation, Seoul, Korea) and statistically evaluated using the Statistica 13.2 software (StatSoft, Inc., Tulsa, OK, USA) using a correlation matrix with a significance level of $\alpha=0.05$ and a tree-clustering analysis.

\section{RESULTS AND DISCUSSION}

The difference in weight increase of individual oils during the storage could be seen in Figure 1, the peroxide and acid values changes are in Figure 2 and Figure 3. Representation of SFA, MUFA and PUFA in oils at the beginning and at the end of the storage are in Figures 4 and Figure 5. Relative contents of the main fatty acids at the beginning (day 0 ) and at the end of experiment (day 40) are given in Table 1. The results of tree-clustering analysis are seen in Figure 6.

Figure 1 shows that according to the relative weight increase the tested oils could be devided into three groups: very oxilable unstable oils - grapeseed and sunflower oils, medium stable oils - frying, rapeseed, corn and rice oils, and very stable oils - olive pomace and sunflower-HO oils. Peroxide number values (Figure 2) again clearly separated very stable oils from the others. Figure 3 shows that though rice and olive oils had higher acid value before the storage test these oils were not subject to such great hydrolytic changes as sunflower and grapseed oils.

The results of the Schaal tests showed the lowest increase in weight gain in olive oil and sunflower oil with increased oleic acid content. On the contrary, the highest increase was in traditional sunflower oil and grape seed oil. Foster, Williamson and Lunn (2009) explained the low oxidative stability of sunflower oil by high levels of linoleic acid and low $\gamma$-tocopherol content. Low $\gamma$-tocopherol content may also contribute to the low stability of grape seed oil as well as its high linoleic acid representation. The increased stability of sunflower-HO oil is due to its high content of oleic acid and the low content of polyunsaturated fatty acids (Smith, King and Min, 2007). The high oleic acid content supported by the presence of a number of non-saponificable components is responsible for the high stability of olive oil (Gunstone, 2005; Firestone, 2005). Olive oil, compared to conventional sunflower oil, also shows good stability under oxidation at $180{ }^{\circ} \mathrm{C}$ for 60 minutes, which Silva et al. (2010) attributed to the high content of phenolic compounds.

The results obtained by monitoring the weight changes of oils correlated with their peroxide values $\left(\mathrm{R}_{2}=0.83\right)$. It is seen from Figure 2 that sunflower and grape seed oils showed a peroxide value decrease after reaching its maximum at about 30 days, i.e., hydroperoxides (primary oxidation products) have already begun to convert to the secondary oxidation products. Corn and frying oils seemd to reach their peroxide value maxima while the rapeseed and rice oils still exhibited the increase in the peroxide number at the day 40 . On the other hand, the increase in the peroxide value of olive oil and high oleic sunflower oil was very small and at the end of the measurement it was far from the propagation stage of the radical chain autooxidation reaction.

It was possible to determine the induction period (IP) in case of grapeseed and sunflower oils, which was 27 (grapeseed oil) and 28 (sunflower oil) days. The IP for frying and rapeseed oils could be estimated around 35 days. The remaining four oils did not show the clear beginning of fast radical chain reaction and had IP over 40 days.

The acid values at the end of experiment correspond to both the relative weight gain $\left(\mathrm{R}_{2}=0.97\right)$ and the the peroxide values $\left(\mathrm{R}_{2}=0.90\right)$. Oils exhibited faster oxidative decomposition have achieved significantly higher acid value (indicating the hydrolytic changes extension) than stable oils at the end of the measurement. Sunflower-HO and olive oils did not show a significant increase in the acid value. On the other hand, the increase between the 20th and the 40th day was significant for other oils. Although the low content of free fatty acids is one of the factors influencing the stability of oils, it is clear from the high initial acidity value of olive oil that this is not the only one determining factor.

Regarding to fatty acid composition (Table 1), the largest decrease during the storage was in PUFA. On the contrary, oleic and palmitic acids relative contents increased. For olive oil, which showed high stability in all previous tests, the change in composition was minimal compared to other oils. It has been confirmed that oils containing less than $10 \%$ of PUFA are significantly more stable than those containing more double bonds (Velíšek, 2014). 


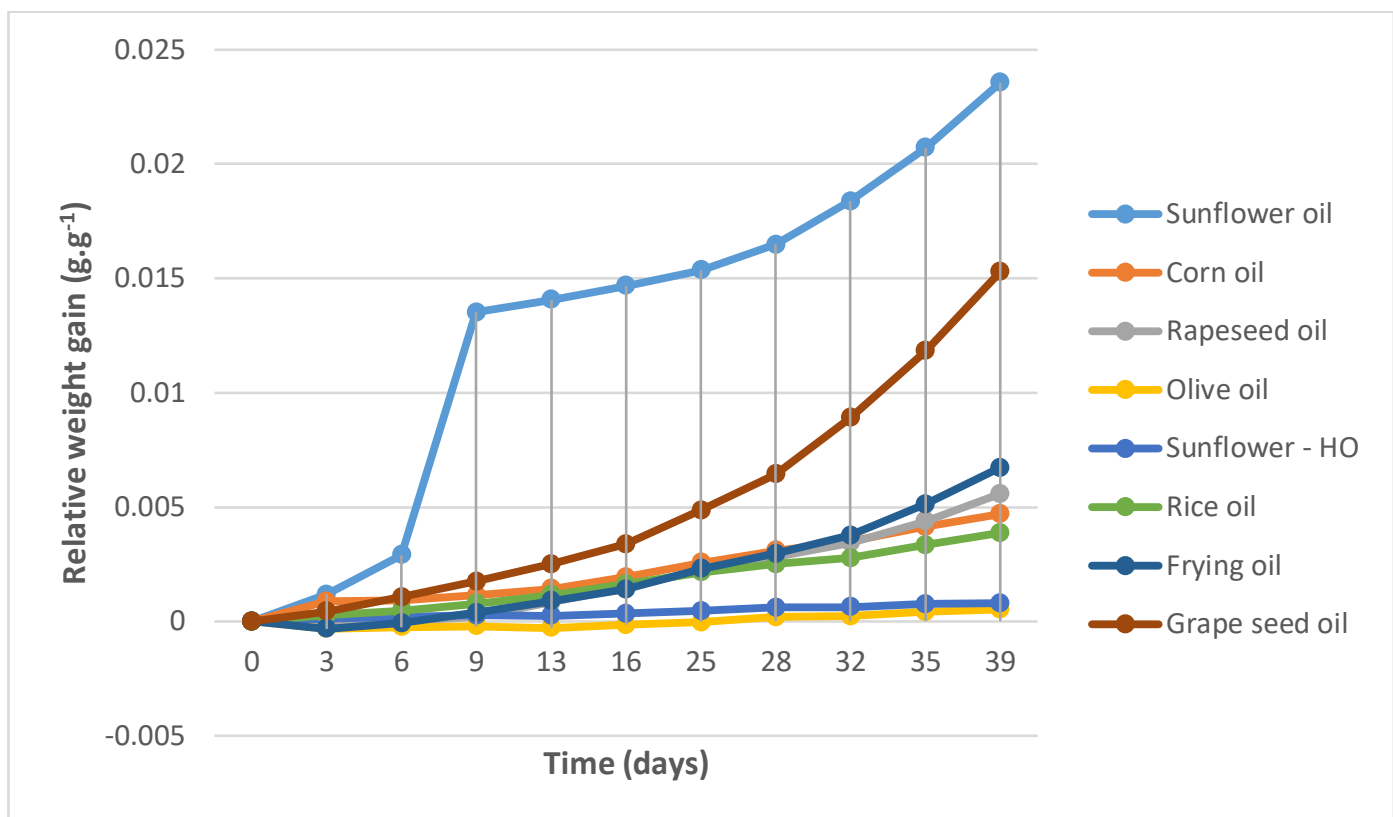

Figure 1 The relative weight changes of individual oils during the Schaal test.

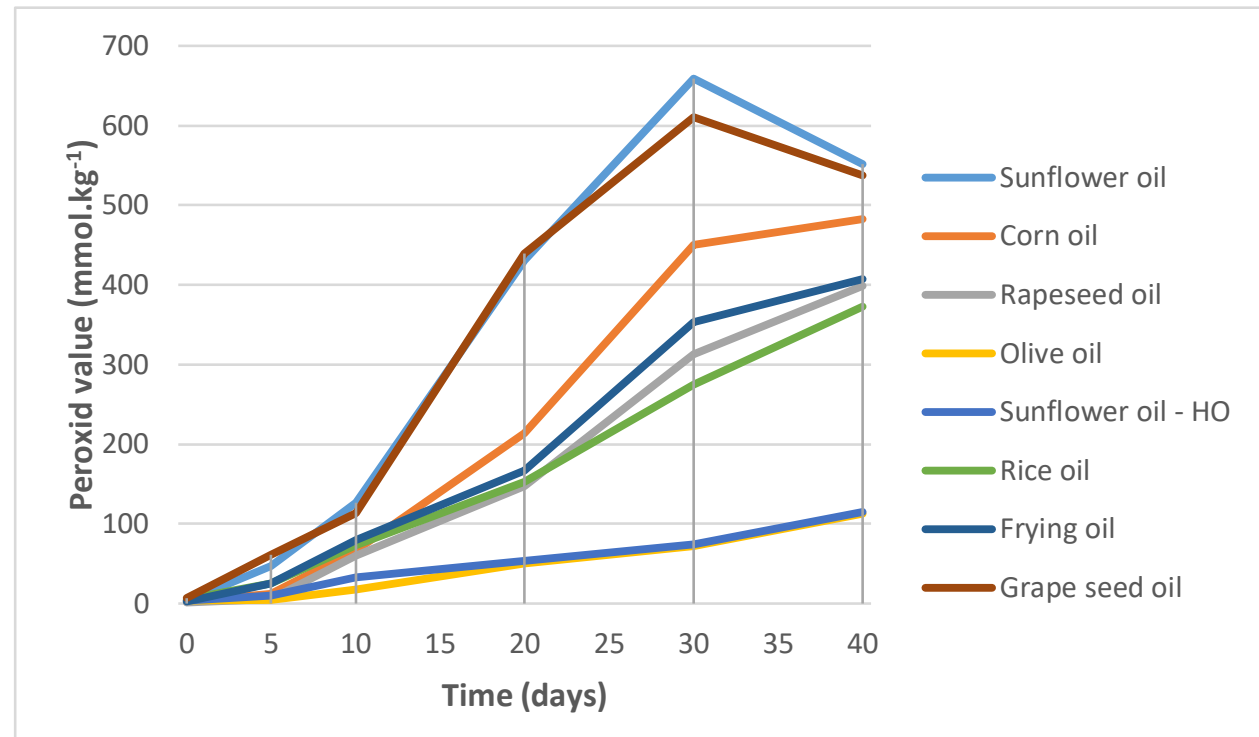

Figure 2 The peroxide value changes of individual oils during the Schaal test.

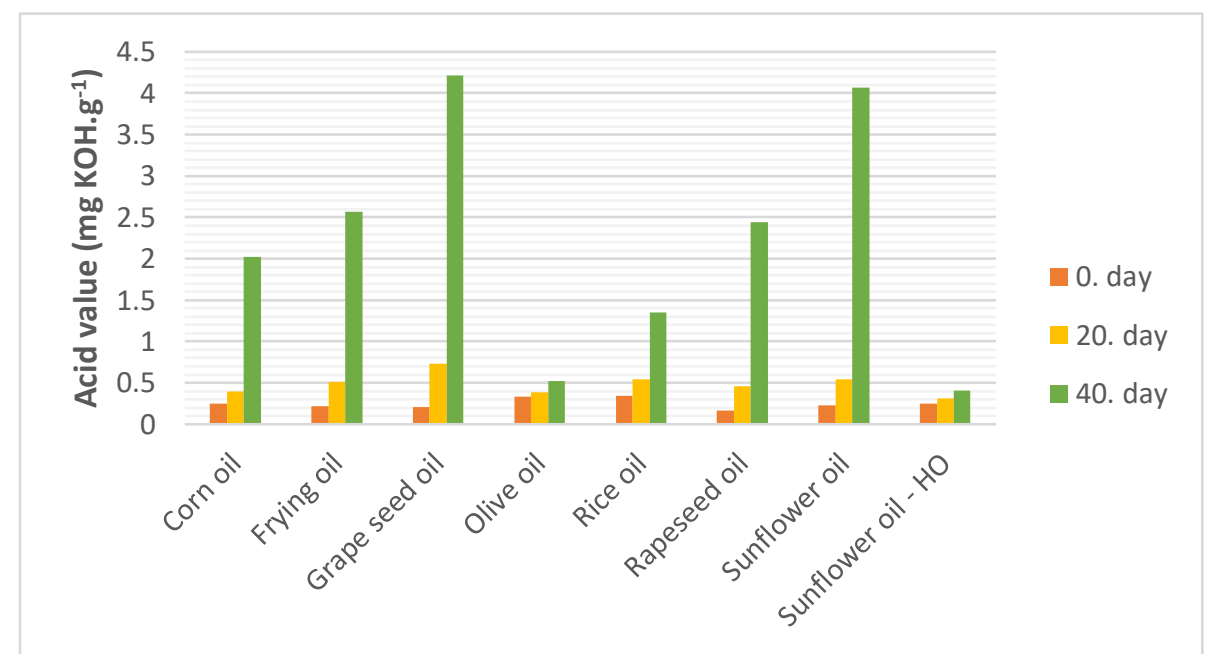

Figure 3 The acid value changes of individual oils during the Schaal test. 


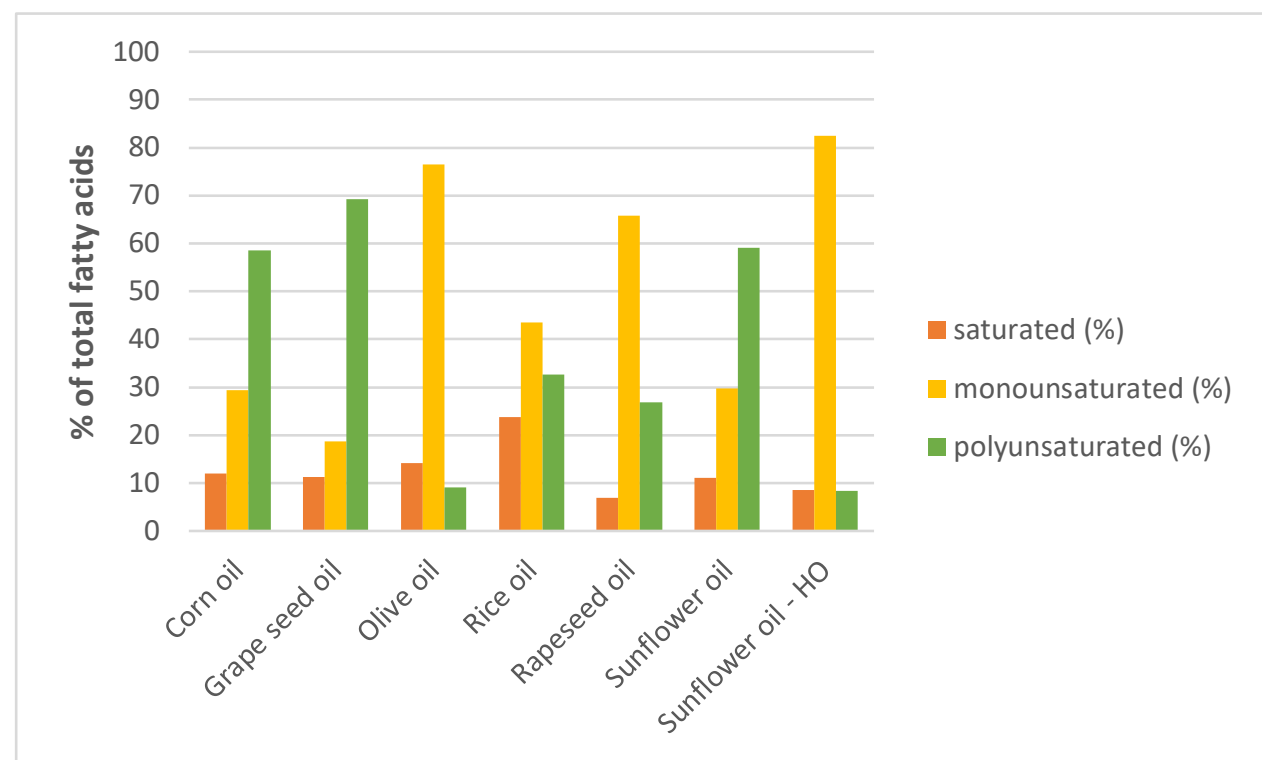

Figure 4 Representation of fatty acids - day 0 .

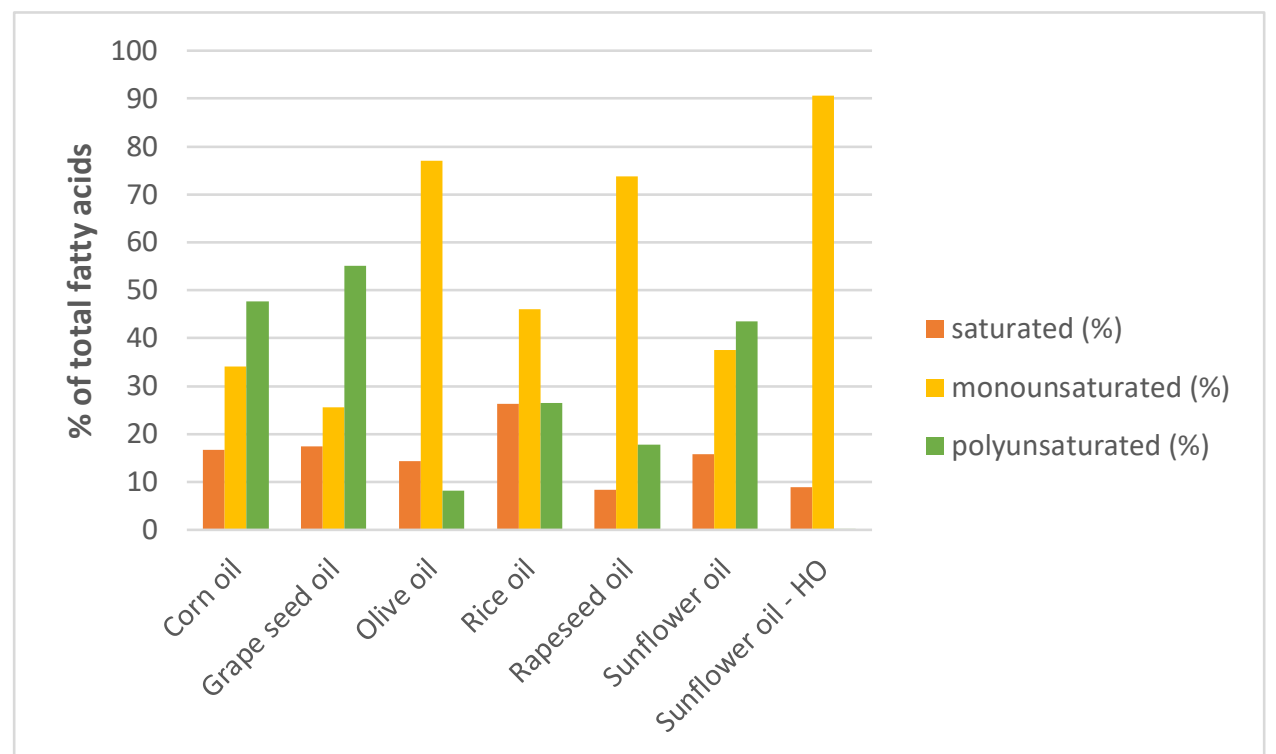

Figure 5 Representation of fatty acids - day 40.

Table 1 Changes of the main fatty acids in oils during the Schaal test.

\begin{tabular}{cccccc}
\hline Oil & \multicolumn{5}{c}{ Fatty acid content (\% of all FA) } \\
\cline { 2 - 6 } & $\begin{array}{c}\text { C16:0 } \\
\text { day 0/day 40 }\end{array}$ & $\begin{array}{c}\text { C18:0 } \\
\text { day 0/day 40 }\end{array}$ & $\begin{array}{c}\text { C18:1 cis-9 } \\
\text { day 0/day 40 }\end{array}$ & $\begin{array}{c}\text { C18:2 cis 9.12 } \\
\text { day 0/day 40 }\end{array}$ & $\begin{array}{c}\text { C18:3 cis-9.12.15 } \\
\text { day 0/day 40 }\end{array}$ \\
\hline Corn & $9.3 / 13.7$ & $1.8 / 2.2$ & $22.9 / 33.6$ & $57.2 / 47.2$ & $0.7 / 0.4$ \\
Grapeseed & $6.8 / 10.3$ & $4.3 / 6.4$ & $18.4 / 25.3$ & $69.1 / 54.8$ & $0.1 /<0.1$ \\
Olive & $10.1 / 10.3$ & $3.1 / 3.1$ & $75.5 / 76.0$ & $8.4 / 7.6$ & $0.6 / 0.5$ \\
Rice & $19.3 / 21.9$ & $2.2 / 2.3$ & $42.6 / 45.2$ & $31.5 / 25.8$ & $1.1 / 0.7$ \\
Rapeseed & $4.3 / 5.3$ & $1.6 / 1.9$ & $63.4 / 71.5$ & $18.6 / 13.8$ & $7.8 / 3.8$ \\
Sunflower & $5.7 / 8.8$ & $3.8 / 5.0$ & $29.5 / 37.2$ & $58.4 / 42.9$ & $0.6 / 0.3$ \\
Sunflower-HO & $3.8 / 4.3$ & $2.8 / 2.9$ & $82.6 / 90.6$ & $8.1 / 0.3$ & $0.3 /<0.1$ \\
\hline
\end{tabular}


Foster, R., Williamson, C. S., Lunn, J. 2009. Culinary oils

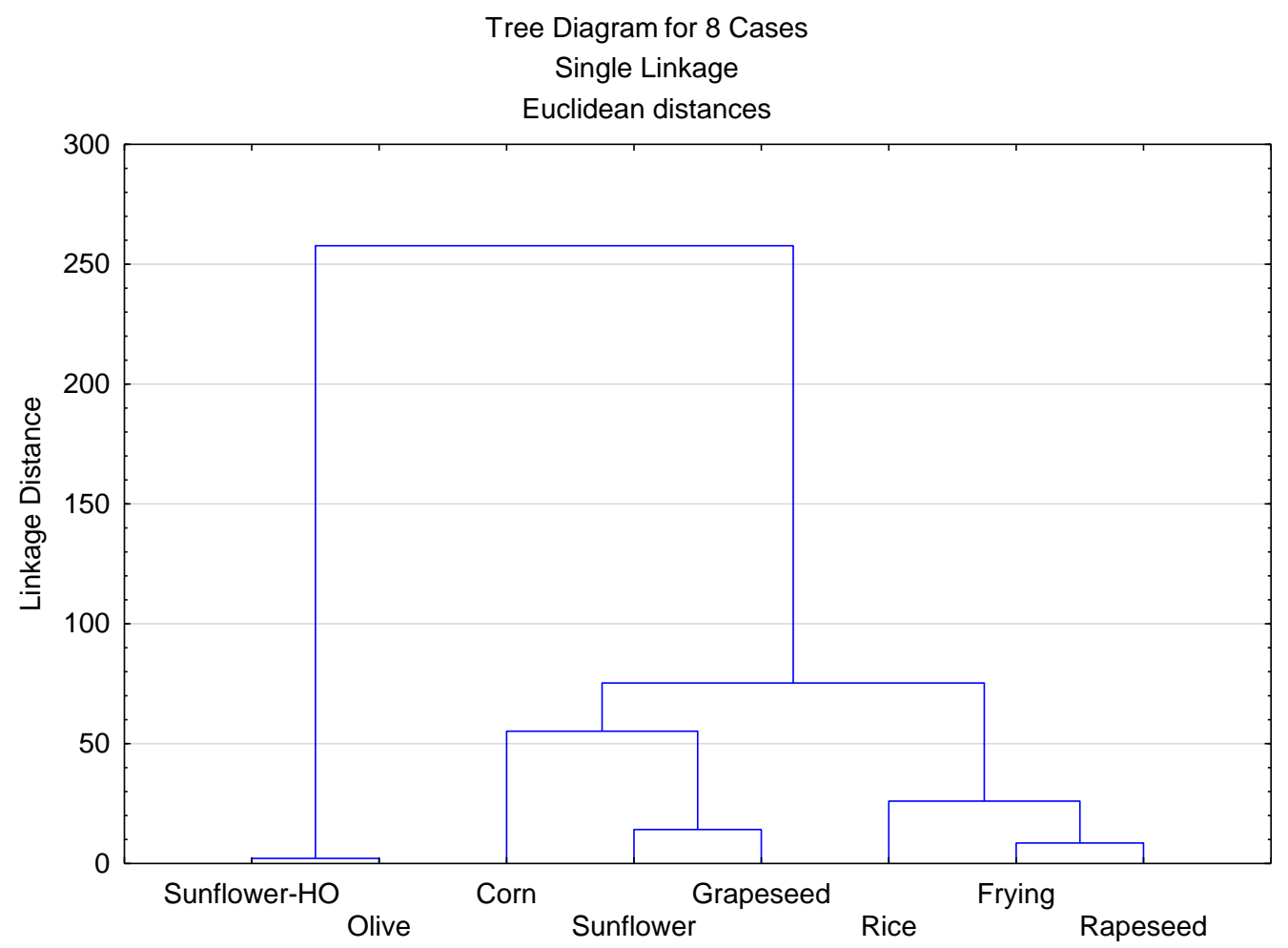

Figure 6 Cluster analysis results of oils - day 40.

A strong negative correlation $\left(\mathrm{R}_{2}=-0.93\right)$ between oleic acid content and oil stability expressed as the peroxide value was found. The significant positive $\left(\mathrm{R}_{2}=0.93\right)$ correlation was found in case of linoleic acid. This confirms the assumption that the oil unsaturation decreases its stability.

Considering the weight gain, peroxide and acid values at the end of experiment alltogether in cluster analysis (Figure 6 ) it can be clearly seen that oils with dominating oleic acid (olive and sunflover-HO) and low degree of polyunsaturation are very distant from all other samples.

\section{CONCLUSION}

The decrease in polyunsaturated acids and the increase in saturated and monounsaturated acids were observed in different kind of oils during their storage at $60{ }^{\circ} \mathrm{C}$. There was a strong negative correlation between oleic acid content and stability expressed by the peroxide value. As well as a strong positive correlation between linoleic acid content. The stability of vegetable oils therefore decreases with increasing amounts of polyunsaturated fatty acids. The initial free fatty acid content does not significantly affect the stability of the oil. In case of the least stable oils (sunflower oil and grapeseed oil), the hydroperoxides began to change to some secondary oxidation products during the monitoring period.

\section{REFERENCES}

Angelovič, M., Jablonický, J., Tkáč, Z., Angelovič, M. 2015. Oxidative stability of fatty acid alkyl esters: A review. Potravinarstvo, vol. 9, no. 1, p. 417-426. https://doi.org/10.5219/500

Firestone, D. 2005. Olive oil. In Shahidi F Bailey's Industrial Oil and Fat Products (6th Edition). New Jersey : John Wiley \& Sons. p. 213-267 ISBN: 978-0-471-38460-1. and their health effects. Nutrition Bulletin, vol. 34, no. 1, p. 4-47. https://doi.org/10.1111/j.1467-3010.2008.01738.x

Guillen, M. D., Cabo, N. 2002. Fourier transform infrared spectra data versus peroxide and anisidine values to determine oxidative stability of edible oils. Food Chemistry, vol. 77 , no. 4, p. 503-510. https://doi.org/10.1016/S03088146(01)00371-5

Gunstone, F. D. 2005. Vegetable oils. In Shahidi F. Bailey's Industrial Oil and Fat Products (6th Edition). New Jersey : John Wiley \& Sons. p. 213-267 ISBN: 978-0-47138460-1.

Choe, E., Min, D. B. 2006. Mechanisms and factors for edible oil oxidation. Comprehensive reviews in food science and food safety, vol. 5, no. 4, p. 169-186. https://doi.org/10.1111/j.1541-4337.2006.00009.x

ISO 3960:2017. Animal and vegetable fats and oils Determination of peroxid value -Iodometric (visual) endpoint determination.

ISO 660:2009. Animal and vegetable fats and oils Determination of acid value and acidity.

Kamal-Eldin, A. 2006. Effect of fatty acids and tocopherols on the oxidative stability of vegetable oils. European Journal of Lipid Science and Technology, vol. 108, no. 12, p. 1051-1061. https://doi.org/10.1002/ejlt.200600090

Matthäus, B. 2010. Oxidation of edible oils. In Decker, E., Elias, R., McClements, D. J. Oxidation in Foods and Beverages and Antioxidant Applications. Management in Different Industry Sectors. Cambridge : Woodhead Publishing. p. 183-238. ISBN: 978-1-84569-983-3. https://doi.org/10.1533/9780857090331.2.183

Silva, L., Pinto, J., Carrola, J., Paiva-Martins, F. 2010. Oxidative stability of olive oil after food processing and comparison with other vegetable oils. Food Chemistry, vol. 


\section{1, no. $4, \quad$ p. $\quad 1177-1187$.} https://doi.org/10.1016/j.foodchem.2010.02.001

Smith, S. A., King, R. E., Min, D. B. 2007. Oxidative and thermal stabilities of genetically modified high oleic sunflower oil. Food Chemistry, vol. 102, no. 4, p. 12081213. https://doi.org/10.1016/j.foodchem.2006.06.058

Velíšek J. 2014. The Chemistry of Food. $1_{\text {st }}$ ed. Chichester, UK : Wiley-Blackwell, 1124 p. ISBN: 978-1118-38381-0.

Žabčíková, S., Červenka, L. 2015. Modified carbon paste electrode as a tool for the evaluation of oxidative stability of rapeseed oil. Potravinarstvo, vol. 9, no. 1, p. 347-351. https://doi.org/10.5219/432

\section{Acknowledgments:}

We would like to thank Ing. Kristina Bryanová for the analysis of samples. This work was supported from European Regional Development Fund No. CZ.02.1.01/0.0/0.0/16_ 019/0000845 and by
METROFOOD-CZ research infrastructure project (MEYS Grant No: LM2018100) including access to its facilities.

\section{Contact address:}

Josef Soukup, Czech University of Life Sciences (CULS), Faculty of Agrobiology, Food and Natural Resource, Department of Microbiology, Nutrition and Dietetics, Kamýcká 129, 16500 Suchdol, Prague, Czech Republic, Tel.: +420 777572 119,

E-mail: soukupjosef@af.czu.cz

ORCID: https://orcid.org/0000-0002-7015-9573

*Lenka Kouřimská, Czech University of Life Sciences (CULS), Faculty of Agrobiology, Food and Natural Resource, Department of Microbiology, Nutrition and Dietetics, Kamýcká 129, 16500 Suchdol, Prague, Czech Republic, Tel.: +420 224383 507,

E-mail: kourimska@af.czu.cz

ORCID: https://orcid.org/0000-0002-1102-7239 